\title{
Analysis of deaths in patients awaiting heart transplantation: impact on patient selection criteria
}

Guy A Haywood, Peter R Rickenbacher, Pedro T Trindade, Lars Gullestad, Joseph P Jiang, John S Schroeder, Randall Vagelos, Philip Oyer, Michael B Fowler

\begin{abstract}
Objective-To analyse the clinical characteristics of patients who died on the Stanford heart transplant waiting list and to develop a method for risk stratifying status 2 patients (outpatients).

Methods-Data were reviewed from all patients over 18 years, excluding retransplants, who were accepted for heart transplantation over an eight year period from 1986 to 1994.

Results-548 patients were accepted for heart transplantation; 53 died on the waiting list, and 52 survived on the waiting list for over one year. On multivariate analysis only peak oxygen consumption (peak $\mathrm{Vo}_{2}$ : 11.7 (SD 2.7) $v 15.1(5.2) \mathrm{ml} / \mathrm{kg} / \mathrm{min}, P=$ $0.02)$ and cardiac output $(3.97(1.03) v 4.79$ (1.06) litres/min, $P=0.04$ ) were found to be independent prognostic risk factors. Peak $\mathrm{Vo}_{2}$ and cardiac index (CI) were then analysed in the last 141 consecutive patients accepted for cardiac transplantation. All deaths and $88 \%$ of the deteriorations to status 1 on the waiting list occurred in patients with either a $\mathrm{CI}<2 \cdot 0$ or $a \mathrm{Vo}_{2}<12$. In those with a $\mathrm{CI}<2 \cdot 0$ and $a \mathrm{Vo}_{2}<12,38 \%$ died or deteriorated to status 1 in the first year on the waiting list. Patients with $\mathrm{CI} \geqslant 2 \cdot 0$ and $a \mathrm{Vo}_{2} \geqslant 12$ all survived throughout follow up. Using a Cox's proportional hazards model with CI and peak $\mathrm{Vo}_{2}$ as covariates, tables were constructed predicting the chance of surviving for (a) 60 days and (b) 1 year on the waiting list.
\end{abstract}

Conclusions-These data provide a basis for risk stratification of status 2 patients on the heart transplant waiting list.

\section{Division of}

Cardiovascular

Medicine and Surgery,

Stanford University

School of Medicine,

Stanford, California,

USA

G A Haywood

P R Rickenbacher

P T Trindade

L Gullestad

J P Jiang

J S Schroeder

R Vagelos

P Oyer

M B Fowler

Correspondence to:

Correspondence

Dr M B Fowler,

Falk Cardiovascular

Research Center, Stan
University School of

niversity School of

Medicine, 300 Pasteur

94305-5246, USA.

94305-5246, USA.

25 October 1995
(Heart 1996;75:455-462)

Keywords: heart failure; prognosis; heart transplantation

Waiting lists for heart transplants are increasing in centres throughout the USA and in many other countries, ${ }^{12}$ the average length of time patients wait before undergoing transplantation is increasing, and the ratio of patients dying on the waiting list to patients being transplanted has risen from 0.07 in 1983 to 0.21 in $1989 .{ }^{3}$ Within the waiting list population the group that suffers most from the worsening imbalance between the demand for transplants and the supply of donor organs is the patients in status 2 (patients not requiring inotropic or mechanical circulatory support) who in most centres are transplanted in the chronological order in which they are accepted on to the waiting list. Patients who present in status 1 (requiring inotropic or mechanical circulatory support) or who deteriorate from status 2 to status 1 , are transplanted ahead of status 2 patients because of their high mortality if they remain on the waiting list on circulatory support. Selecting status 1 patients for urgent transplantation has been shown to be an appropriate use of donor organs in terms of the impact on overall mortality, ${ }^{4}$ but has resulted in a high percentage of donor organs that become available going to these severely ill patients, with fewer organs remaining for implantation into status 2 patients.

In this study we examined the mortality in all patients on the waiting list for heart transplant over an eight year period in order to define the length of time that patients who died had been waiting and to determine how many of the deaths occurred in patients who had progressed from status 2 to status 1 . We also compared two groups from within the status 2 patients on the waiting list who were at opposite ends of the spectrum for prognostic risk: those who died on the waiting list; and those who survived for more than one year on the waiting list without adverse outcome. By using this approach it was possible to identify clinical variables that were independent prognostic indicators and to propose a strategy to improve our ability to target the available donor organs for transplant not only to status 1 patients, but also to status 2 patients with a high risk of death on the waiting list. The policy suggested has the potential to decrease overall mortality in patients referred for heart transplant and to avoid performing heart transplants on patients who are unlikely to gain survival benefit from the procedure.

\section{Methods}

The study was a retrospective review of the clinical records of patients aged 18 years or older who were placed on the Stanford University Hospital heart transplant waiting list between 1 June 1986 and 31 May 1994. Patients who were accepted for repeat heart transplants were excluded from the study. Data drawn from the pretransplant evaluation database were supplemented from the clinical files which are kept for each patient referred for heart transplantation. In instances where 
Table 1 Data collected for univariate and multivariate analysis. Peak $\mathrm{VO}_{2}$ was measured using a ramp protocol at 10 watts/min in all patients using an electrically braked bicycle ergometer coupled to a metabolic measurement cart

Age

Diagnosis (ischaemic, dilated, valvular or other)

Resting heart rate

Systolic blood pressur

Ejection fraction

Serum sodium

Serum creatinine

ACE inhibitor therapy

Central haemodynamics:

Cardiac output

Systolic pulmonary artery pressure

Mean pulmonary artery pressure

Pulmonary capillary wedge pressure

Pulmonary vascular resistance

Exercise variables:

Percentage of maximum predicted heart rate achieved at peak exercise

Peak oxygen consumption on exercise

Arrhythmias:

History of a sustained supraventricular or ventricula

arrhythmia (including atrial firbrillation, but excluding

frequent ectopy)

Antiarrhythmic drug administration (other than digoxin)

the clinical variables to be assessed were incomplete in these files, the inpatient hospital medical records were reviewed.

In the first phase of the study data were used to define the two patient groups: status 2 patients who died on the waiting list; and status 2 patients who survived for more than one year on the waiting list without adverse outcome. Accepted outcomes in the latter group were: heart transplantation; removal from the waiting list because of clinical improvement; or continued listing for transplantation at the end of the study period without deterioration to status 1 . This analysis was performed in February 1994 and the two subgroups were taken from patients accepted onto the waiting list between 1 June 1986 and 31 December 1993. Data collected from these two subgroups are shown in table 1 . These data was subjected to univariate and multivariate analysis.

To devise a formula enabling the prognostic indicators identified by this technique to be used in risk stratification of status 2 patients, we then performed a further analysis on all patients in status 2 at entry who were accepted onto the waiting list between 1 January 1991 and 31 May 1994. (Thirty six of the patients in this cohort of 114 consecutive patients were also used as part of the first phase subgroup analysis.) This time period was used to ensure that the formula would be based on patients who had received modern medical treatment for heart failure. Statistical analyses using Kaplan Meier survival curves and a Cox's proportional hazards model were performed.

STATISTICAL METHODS

All data were entered into Statview 4.01 (Abacus Concepts). Differences between the two subgroups (6/86-12/93) in which multiple clinical variables were assessed (patients who died on the list and patients who survived for over one year) were analysed using the two tailed Mann-Whitney U test for continuous variables and $\chi^{2}$ square test for nominal vari- ables. Significance was measured at the 5\% level. Variables that were found to have significantly different mean values or rates in the two subgroups on univariate analysis were then subjected to multivariate analysis using a least squares analysis (Statview 4.01, Abacus Concepts) and a stepwise logistic regression analysis (SPSS for Windows release 5) to determine which factors were independently associated with outcome.

From the consecutive patient cohort (1/91 to 5/94) Kaplan Meier survival curves were constructed using Survival tools for Statview 1.0 (Abacus Concepts). Times of death or deterioration to status 1 were recorded as event times and removal from the waiting list because of transplantation, or any other reason, was treated as a censoring event. Dichotomisation points for the independent prognostic variables identified by multivariate analysis were used to compare patients with values above and below the selected values. Differences in survival were determined using a log rank (Mantel Cox) test. In addition, a Cox proportional hazard model was constructed using the same independent prognostic variables as covariates. Tables giving the predicted chance of surviving for (a) 60 days and (b) one year on the waiting list without death or deterioration to status 1 were calculated for a range of combinations of individual values of the independent prognostic variables using the equation:

Chance of survival to time $t=\left[S_{0}(t)\right]^{\exp \left(b^{\prime} x^{\prime}+b^{\prime} x^{\prime \prime}\right)}$ where $S_{0}(t)=$ the baseline survival function, $b^{\prime}=$ the coefficient of hazard calculated for the first prognostic variable, $b^{\prime \prime}=$ the coefficient of hazard for the second prognostic variable, and $x^{\prime}$ and $x^{\prime \prime}=$ differences from the baseline values for each value respectively. Values in text and table 2 are given as mean (SD)

\section{Results}

DEMOGRAPHIC ANALYSIS

A total of 1114 patients was assessed in the period from June 1986 to December 1993, and from these 548 ( $49 \%$ of the total) were accepted onto the waiting list. During the same study period 53 died on the waiting list, giving a waiting list mortality rate of $9 \cdot 7 \%$. Mortality has been rising during this period, as shown by comparison with the figures for 1 January 1991 to 31 May 1994, during which time 23 patients $(16 \%)$ died. Mean time on the waiting list for patients accepted between June 1986 and 31 December 1993 was 127 d, whereas from 1 January 1991 to 31 May 1994 the mean waiting time was $272 \mathrm{~d}$.

\section{Criteria for acceptance for heart transplantation}

The majority of patients accepted on to the heart transplant waiting list had been referred because of severe ventricular dysfunction and recurrent or refractory symptoms of congestive heart failure. Small numbers of patients were also accepted who had severe recurrent angina pectoris or ventricular tachyarrhythmias which 
Figure 1 Time distribution of deaths of patients listed as status 2 on the heart transplant waiting list; $69 \%$ of all deaths in status 2 occurred in the first 2 months; $66 \%$ of all status 2 deaths were sudden cardiac deaths.

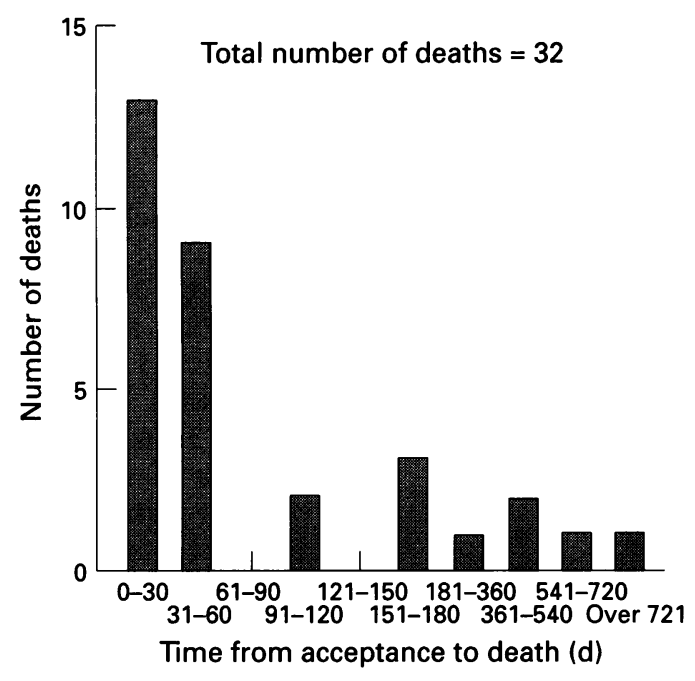

were considered technically unsuitable or an unacceptable risk for other forms of treatment including surgical intervention. Patients were excluded if they were suffering from significant co-morbid conditions that were likely to limit life expectancy independently to less than five years. Other exclusions were pharmacologically irreversible pulmonary hypertension (pulmonary vascular resistance greater than three Wood units despite intravenous sodium nitroprusside), a history of severe psychiatric illness, continuing drug or substance abuse, or other severe psychosocial dysfunction. During the period January 1991 to May 1994 the mean cardiac output and peak oxygen consumption of status 2 patients on medical treatment was $2 \cdot 1(\mathrm{SD} 0.6)$ litres $/ \mathrm{min} / \mathrm{m}^{2}$ and 13.6 (3.8) $\mathrm{ml} / \mathrm{kg} / \mathrm{min}$ respectively. At the time these measurements were made, $86 \%$ were receiving angiotensin converting enzyme (ACE) inhibitor therapy.

\section{Death rate}

Twenty one of the 53 deaths that occurred between June 1986 and December 1993 were patients who were classified as status 1 at the time of acceptance, and 32 were patients who were status 2 when accepted on to the waiting list. The time distribution of deaths in the status 2 patients is shown in fig 1 . The bulk of the deaths occurred early after acceptance onto the list; $69 \%$ of all deaths in status 2 patients occurred in the first two months after acceptance. Ten patients who were status 2 at the time of acceptance progressed to status 1 before death on the waiting list $(19 \%$ of all those who died; fig 2). A high proportion of

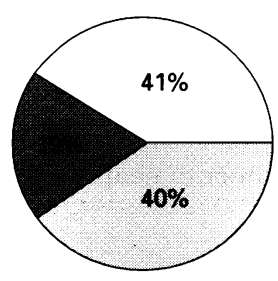

Status 1 from assessment to death Status 2 at assessment, Status 1 at death Status 2 from assessment to death [Status 1 at assessment, Status 2 at death, none]

Figure 2 Distribution of deaths by patient status from the time of assessment and acceptance onto the waiting list until the time of death. the status 2 deaths $(66 \%)$ were sudden cardiac deaths.

\section{Univariate analysis}

Table 2 shows a comparison of the clinical variables measured in status 2 patients who died on the waiting list $(n=32)$ compared with those of status 2 patients who survived for more than one year on the waiting list without an adverse outcome $(n=52)$. With univariate analysis using a two tailed Mann Whitney U test there were four variables that showed a significant difference between the two groups: systolic blood pressure, cardiac output, peak oxygen consumption, and serum sodium. Differences in other variables such as ejection fraction, pulmonary capillary wedge pressure (PCWP) and pulmonary vascular resistance (PVR) did not reach significance. The two groups were closely matched for age $(51.3$ $(9 \cdot 0)$ in those who died, $51.2(9 \cdot 2)$ in those who survived). In addition to these variables we compared: gender, aetiology of heart failure, arrhythmic history, and ACE inhibitor treatment. Patients were predominantly male in both groups $(88 \%$ of those who died, $96 \%$ of those who survived, NS), ischaemic heart disease was the commonest diagnosis in each group $(63 \% v 65 \%$, NS) with the next commonest aetiology being idiopathic dilated cardiomyopathy ( $28 \%$ v $25 \%$, NS). There was also no significant difference in the frequency of a history of arrhythmia (59\% in patients who died, $v 49 \%$ in those who survived, NS) or in the proportion of patients receiving ACE inhibitor treatment ( $86 \%$ in patients who died, $v 88 \%$ in those who survived, NS).

\section{MULTIVARIATE ANALYSIS}

Multivariate analysis of systolic blood pressure, cardiac output, peak oxygen consumption, and serum sodium revealed that only cardiac output ( $P=0.023$ by logistic regression analysis $)$ and peak $\mathrm{Vo}_{2}(\mathrm{P}=0.012$ by logistic regression analysis) were independently associated with adverse outcome, whether tested by a least squares or stepwise logistic regression analysis.

Because three of the status 2 patients who died while on the waiting list survived for more than one year on the list before death, data were also analysed excluding these three patients. There was no significant change in the results when these three patients were excluded.

\section{SURVIVAL CURVE ANALYSIS}

A total of 141 consecutive patients over 18 years of age who were first time candidates for heart transplantation, accepted onto the waiting list between 1 January 1991 and 31 May 1994 , were subjected to survival curve analysis. These 141 patients represented $25 \%$ of the 570 assessed during this time. By the end of the period, $74(52 \%)$ of the patients had been transplanted, $23(16 \%)$ died on the waiting list, a further $16(11 \%)$ deteriorated from status 2 to status 1 before transplantation, $12(9 \%)$ were removed from the waiting list because their clinical status had improved, and 32 
Table 2 Comparison of patients awaiting first time transplantation who were classified as status 2 at the time of acceptance onto the heart transplant waiting list and who subsequently died on the list $(n=32)$, and patients from the group who survived for a period of over one year on the waiting list without deterioration to status $1(n=52)$ (univariate analysis). Values are means (SD)

\begin{tabular}{|c|c|c|c|}
\hline & $\begin{array}{l}\text { Waiting list } \\
\text { deaths }\end{array}$ & $\begin{array}{l}\text { Waiting list } \\
\text { survivors }\end{array}$ & $P$ value \\
\hline $\begin{array}{l}\text { Age (years) } \\
\text { Resting heart rate (beats/min) } \\
\text { \%Maximum heart rate } \\
\text { Systolic blood pressure }(\mathrm{mm} \mathrm{Hg}) \\
\text { SPAP† (mm Hg) } \\
\text { Mean PAP } ¥(\mathrm{~mm} \mathrm{Hg}) \\
\text { PCWPS }(\mathrm{mm} \mathrm{Hg})\end{array}$ & $\begin{array}{l}51 \cdot 3(9 \cdot 0) \\
88(13) \\
73(14) \\
98(16) \\
51(13) \\
35(10) \\
23(7)\end{array}$ & $\begin{array}{l}51 \cdot 2(9 \cdot 2) \\
84(16) \\
80(15) \\
106(14) \\
45(13) \\
32(9) \\
22(9)\end{array}$ & $\begin{array}{l}0.89 \\
0 \cdot 15 \\
0 \cdot 27 \\
0 \cdot 01 \\
0 \cdot 09 \\
0 \cdot 15 \\
0.53\end{array}$ \\
\hline $\begin{array}{l}\text { Pulmonary vascular resistance } \\
\text { (Wood units) } \\
\text { Cardiac output (litres/min) } \\
\text { Ejection fractionף (\%) } \\
\text { Peak Vo } 1 / \text { (ml/kg) } \\
\text { Serum creatinine }(\mu \mathrm{mo} / \mathrm{litre}) \\
\text { Sodium (mmol/litre) } \\
\text { Antiarrhythmics (\%) }\end{array}$ & $\begin{array}{c}3 \cdot 3(2 \cdot 2) \\
3 \cdot 94(1 \cdot 16) \\
17(8) \\
11 \cdot 8(3 \cdot 1) \\
122 \cdot 0(26 \cdot 5) \\
135 \cdot 6(4 \cdot 5) \\
59\end{array}$ & $\begin{array}{l}2 \cdot 6(2 \cdot 5) \\
4 \cdot 81(1 \cdot 06) \\
18(7) \\
15 \cdot 3(5 \cdot 2) \\
114 \cdot 0(26 \cdot 5) \\
138 \cdot 0(4 \cdot 3) \\
49\end{array}$ & $\begin{array}{l}0 \cdot 08 \\
0 \cdot 0004 \\
0 \cdot 34 \\
0 \cdot 02 \\
0 \cdot 16 \\
0 \cdot 035 \\
039\end{array}$ \\
\hline
\end{tabular}

*Percent of predicted maximum heart rate achieved.

†SPAP, systolic pulmonary artery pressure.

†Mean pulmonary artery pressure.

†Mean pulmonary artery pressure.

ףLulmonary capillary wedge press

||Peak oxygen consumption on treadmill exercise.
Values for cardiac index and peak $\mathrm{Vo}_{2}$ at the time of acceptance were collected for all patients initially in status 2 ( $n=114$ patients). Cardiac index measurements were present for $100 \%$ of the patients accepted, and peak $\mathrm{Vo}_{2}$ had been assessed at the time of acceptance in $94(82 \%)$. Cardiac index measurements ranged from 1.15 to 3.86 (mean $2 \cdot 1(0.56)$ ) litres $/ \mathrm{min} / \mathrm{m}^{2}$, and peak $\mathrm{Vo}_{2}$ from $5 \cdot 7$ to 23.9 (mean $13.6(3.8)$ ) $\mathrm{ml} / \mathrm{kg} / \mathrm{min}$. There were nine patients with cardiac index greater than or equal to $3 \mathrm{litres} / \mathrm{min} / \mathrm{m}^{2}$ and eight with peak $\mathrm{VO}_{2} \max \geqslant 20 \mathrm{ml} / \mathrm{kg} / \mathrm{min}$. We found that status 2 patients with a CI $\geqslant 2$ litres $/ \mathrm{min} / \mathrm{m}^{2}$ at the time of acceptance had a one year survival free from death or deterioration to status 1 of $83 \%$. Status 2 patients with $\mathrm{Vo}_{2} \geqslant 12 \mathrm{ml} / \mathrm{kg} /$ min had a one year survival free from death or deterioration to status 1 of $82 \%$. In both cases survival above and below the dichotomisation points were highly significantly different (fig 3). Neither variable on its own identified all of those who died while on the waiting list. We therefore tried two strategies based on these dichotomisation points: (1) selecting a group in which cardiac index was less than 2.0 litres/ $\mathrm{min} / \mathrm{m}^{2}$ and peak $\mathrm{Vo}_{2}$ was less than $12 \mathrm{ml} / \mathrm{kg} /$ $\mathrm{min}$, and (2) selecting patients in whom cardiac index was $\geqslant 2.01 / \mathrm{min} / \mathrm{m}^{2}$ and peak $\mathrm{Vo}_{2}$ was $\geqslant 12 \mathrm{ml} / \mathrm{kg} / \mathrm{min}$. The intention of the first strategy was to attempt to define high risk patients to be given priority. The intention of the second strategy was to identify patients with a good prognosis in whom transplantation could be deferred, allowing resources to be concentrated on higher risk patients. The percentage of patients identified by these two different strategies is shown in table 3.

The highest risk group with cardiac index less than 2.0 litres $/ \mathrm{min} / \mathrm{m}^{2}$ and peak $\mathrm{Vo}_{2}$ less than $12 \mathrm{ml} / \mathrm{kg} / \mathrm{min}$ had a very poor prognosis, with $38 \%$ either dying or deteriorating to status 1 during their first year on the waiting list. Although this group was small, containing only $19 \%$ of all status 2 patients on the waiting list, it contained $38 \%$ of all patients who died. Conversely, a strategy of selecting patients in
Figure 3 Cumulative survival (Kaplan-Meier curves) without death or deterioration to status 1 in patients who were classified as status 2 at the time of acceptance. (Peak $\mathrm{VO}_{2}=$ peak oxygen consumption presults shown for the 94 patients with peak oxygen consumption measured at the time of acceptance). Time from acceptance is shown in days. Percentage survival at one year is shown.
(23\%) were stable and still waiting for trans-

Survival curve analysis in relation to peak $\mathrm{VO}_{2}$ placement on the waiting list

In constructing Kaplan Meier survival peak $\mathrm{VO}_{2}$ or cardiac index, we chose to anal teath and deterioration in status from allowed us to develop a strategy designed not only to decrease mortality on the waiting list, but also to reduce the number of patients detelantation. In addition it ensured that the pevent, transplantation, was affected by non-uniform alterations in clini deterioration to status 1 as an end point only factors affecting the likelihood of undergoing transplantation were time from acceptance onto the waiting list and the availability of a donor organ of the correct blood group.
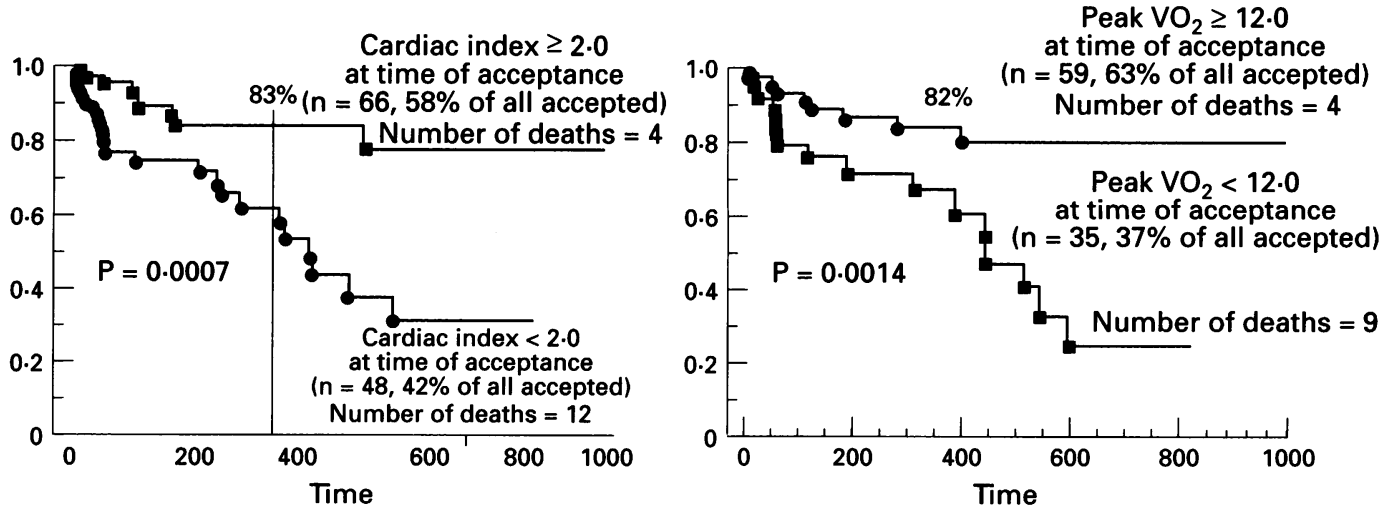
Table 3 Percentage of status 2 patients defined by combinations of values for cardiac index (CI: litres $\left./ \mathrm{min} / \mathrm{m}^{2}\right)$ and peak oxygen consumption $\left(\mathrm{VO}_{2}\right.$ max: $\mathrm{ml} / \mathrm{kg} / \mathrm{min}$ ) as percentages of: (1) all status 2 patients in whom measurements of both cardiac index and peak oxygen consumption were made at the time of acceptance for heart transplantation $(n=94)$, (2) all status 2 patients in whom measurements of both cardiac index and peak oxygen consumption were made at the time of acceptance for heart transplantation who died on the waiting list $(n=13),(3)$ all status 2 patients in whom measurements of both cardiac index and peak oxygen consumption were made at the time of acceptance for heart transplantation who either died or deteriorated to status 1 while on the waiting list $(n=26)$

\begin{tabular}{|c|c|c|}
\hline & $\begin{array}{l}C I<2 \cdot 0 \text { and } \\
V \mathrm{O}_{2} \max <12 \\
(n=18)\end{array}$ & $\begin{array}{l}C I \geqslant 2 \cdot 0 \text { and } \\
V_{O_{2}} \max \geqslant 12 \\
(n=37)\end{array}$ \\
\hline $\begin{array}{l}\text { Percent of all accepted } \\
\text { Percent of deaths } \\
\text { Percent of } \\
\text { deteriorations to } \\
\text { category } 1 \text { and/or deaths }\end{array}$ & $\begin{array}{l}19 \% \\
38 \%\end{array}$ & $\begin{array}{r}39 \% \\
0 \%\end{array}$ \\
\hline
\end{tabular}

whom cardiac index was $\geqslant 2.01 / \mathrm{min} / \mathrm{m}^{2}$ and peak $\mathrm{VO}_{2}$ was $\geqslant 12 \mathrm{ml} / \mathrm{kg} / \mathrm{min}$ identified a moderately large group of status 2 patients $(37 / 94,39 \%)$ in whom the prognosis was remarkably good with no deaths and only $12 \%$ deteriorating to status 1 on the waiting list (table 3). (Three of the 20 status 2 patients in whom peak $\mathrm{VO}_{2}$ measurements were not made at the time of acceptance died; all had CI $<2.0$ litres $/ \mathrm{min} / \mathrm{m}^{2}$.) Analysis of the survival curves for the groups selected by the two strategies and for the remainder of the status 2 population is shown in fig 4.

Cox's proportional hazards model in relation to peak $\mathrm{VO}_{2}$ and cardiac index in status 2 patients The coefficient of hazard for a unit increase from a baseline cardiac index of 2.0 litres $/ \mathrm{min} /$ $\mathrm{m}^{2}$ was -1.493 and the coefficient of hazard

Table 4 Survival functions at $60 \mathrm{~d}$ and at one year derived from a Cox proportional hazards model for different values of cardiac index (CI) and peak oxygen consumption (peak $\mathrm{VO}_{2}$ )

\begin{tabular}{|c|c|c|c|c|c|c|c|c|c|c|c|c|c|c|c|c|c|c|c|c|c|c|c|c|c|c|}
\hline \multirow[b]{2}{*}{$\mathrm{Peak} \mathrm{VO}_{2}$} & \multicolumn{6}{|c|}{ Cardiac index } & \multicolumn{20}{|c|}{ Change of survival for 60 days free from death or deterioration to status 1} \\
\hline & $1 \cdot 0$ & $1 \cdot 1$ & $1 \cdot 2$ & $1 \cdot 3$ & $1 \cdot 4$ & $1 \cdot 5$ & $1 \cdot 6$ & $1 \cdot 7$ & $1 \cdot 8$ & 1.9 & $2 \cdot 0$ & $2 \cdot 1$ & $2 \cdot 2$ & $2 \cdot 3$ & $2 \cdot 4$ & $2 \cdot 5$ & $2 \cdot 6$ & $2 \cdot 7$ & $2 \cdot 8$ & $2 \cdot 9$ & $3 \cdot 0$ & $3 \cdot 1$ & $3 \cdot 2$ & $3 \cdot 3$ & $3 \cdot 4$ & \\
\hline & 6 & & 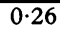 & 31 & 0.36 & 0 & 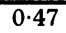 & 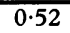 & 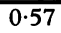 & 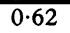 & 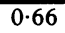 & 0.70 & $\cdot 74$ & 8 & $0 \cdot 80$ & $\cdot 82$ & $\overline{84}$ & 0.86 & 88 & 0.90 & 0.91 & 0.92 & .93 & 0.94 & 0.95 & \\
\hline & & & & & & & & & & & & & & & & & & & & & & & & & & \\
\hline & & 7 & 0.33 & $0 \cdot 38$ & 0 & & & & & & 0.71 & & 78 & & & & & & & & & & & & & \\
\hline & 5 & 1 & 0.36 & 0.42 & 0.47 & 0.52 & & 0.62 & 0.66 & $0 \cdot 70$ & 0.73 & & & & & & $0 \cdot 88$ & & 0.91 & & 0.93 & & 5 & & & \\
\hline & 9 & 4 & & 0.45 & 0.50 & 0.55 & 0.60 & 0.65 & 0 & 0.72 & 0.76 & & & & & & 0.89 & & & & & & & & & \\
\hline & 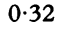 & 38 & 0.43 & 0.49 & 0.54 & & & 0. & 0 & & & & & & & & & & & & & & & & & \\
\hline & & 0.41 & 0.47 & 0.52 & 0.57 & 0.61 & 0 . & 0.70 & 0.73 & & 0.79 & & & & & & 0.91 & & & & & & & & & \\
\hline & & 0 & 0.50 & $0 \cdot 55$ & 0.60 & & & 0.72 & & & & & & & & & & & & & & & & & & \\
\hline & & 0 & 0 & 0.58 & 0.63 & 0.67 & & 0.74 & 0 & & & & & & & & 0.93 & & & & & & & & & \\
\hline 1 & & 0 & 0.5 & 0.61 & 0.66 & 0 & & & & & & & & & & & & & & & & & & & & \\
\hline$\cdot$ & & 0 & & 0.64 & 0.68 & 0 & & 0. & $0 \cdot 81$ & & 0 . & & 9 & 0 & 0 & & 0.94 & & & & 0.97 & & 0.97 & 8 & 8 & \\
\hline & & 0 & 0.63 & 0.67 & & 0 & & & & & & & & & & & & & & & & & & & & \\
\hline & & 0.61 & & 0.69 & 0 & 0 . & & 0 & 0.84 & & 0 . & 0 & 0 & & & 0 & 0 & & 0 & 0 & 0 . & 0 & 0.98 & ( & 0 & \\
\hline & & 0. & & 0.72 & & & & & & & & & & & & & & & & & & & & & & \\
\hline 1 & & 0.67 & 0.7 & 0 . & 0 . & 0 . & & 0 & 0 & & 0 . & 1 & 0 & & & & 0 & & 0 & 0 & & & 0 & & 0 & \\
\hline & & 0.69 & 0.7 & & & & & & & & & & & & & & & & & & & & & & & \\
\hline & & 0 & 0 . & & 0 & & & 0 & 0 . & & 0 & & 0 & & & & 0 & & & & & & 0 & 0 & 0 & \\
\hline & & 0 & 0 & & & & & & & & & & & & & & & & & & & & & & & \\
\hline & & 0 & 0 . & 0 & & & & & 0 & & 0 . & & 0 & & & 0 & 0 & & 0 & 0 & 0 & 0 & 0 & ( & 0 & \\
\hline & & 0 . & & & & & & & & & & & & & & & & & & & & & & & & 0 . \\
\hline & & 0 & & & & & & & 0 & & 0 & & 0. & 0 & & 0 & 0 & 0. & 0 & & 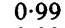 & 0 & 0 & 0 & 0.99 & 0 . \\
\hline & & 0 & & & & & & & & & & & & & & & & & & & & & & & & $0 \cdot$ \\
\hline & & $0 \cdot \varepsilon$ & & 0 . & & 0 . & & & & & & & & & & & & & & & & & & 0 & 0.99 & \\
\hline & & & & & & & & & & & & & & & & & & & & & & & & & 0.99 & 1 . \\
\hline & & 0.86 & $0 \cdot \varepsilon$ & $0 \cdot \varepsilon$ & 0 & 0 . & & & 0 & & 0 . & & & & & & & & & & & & & & $1 \cdot 0$ & \\
\hline & & & & & & & & & & & 0 . & & & & & & & & & & & & & 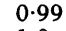 & 1. & 1) \\
\hline & & $0 \cdot \varepsilon$ & 0 & 0.5 & & & & & & & 0. & & & & & & & & & & & & 0.99 & 1 & 1.0 & \\
\hline & & $0 . \varepsilon$ & & & & & & & & & & & & & & & & & & & & & 1.0 & & $1 \cdot 0$ & 1.0 \\
\hline & & & 0 & 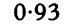 & & 0. & & & 0 & 7 & 0. & 0 & 0.98 & & & & 9 & 等 & 0.99 & & 0.99 & 0.99 & 1.0 & . & 1.0 & 10 \\
\hline
\end{tabular}

Change of survival for 1 year free from death or deterioration to status 1

Cardiac index

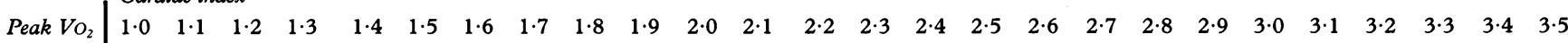

6.0

6.5

$\begin{array}{llllllllllllllllllllllllllllll}0.02 & 0.03 & 0.05 & 0.07 & 0.10 & 0.14 & 0.19 & 0.24 & 0.29 & 0.34 & 0.40 & 0.45 & 0.50 & 0.55 & 0.60 & 0.65 & 0.69 & 0.72 & 0.76 & 0.79 & 0.81 & 0.84 & 0.86 & 0.88 & 0.89 & 0.91\end{array}$ $\begin{array}{lllllllllllllllllllllllllll}0.02 & 0.04 & 0.06 & 0.09 & 0.13 & 0.17 & 0.22 & 0.27 & 0.32 & 0.38 & 0.43 & 0.49 & 0.54 & 0.59 & 0.63 & 0.67 & 0.71 & 0.74 & 0.78 & 0.80 & 0.83 & 0.85 & 0.87 & 0.89 & 0.90 & 0.91\end{array}$ $\begin{array}{llllllllllllllllllllllllllll}0.03 & 0.05 & 0.08 & 0.12 & 0.16 & 0.20 & 0.25 & 0.30 & 0.36 & 0.41 & 0.47 & 0.52 & 0.57 & 0.62 & 0.66 & 0.70 & 0.73 & 0.77 & 0.79 & 0.82 & 0.84 & 0.86 & 0.88 & 0.90 & 0.91 & 0.92 \\ 0.05 & 0.07 & 0.10 & 0.14 & 0.18 & 0.23 & 0.29 & 0.34 & 0.39 & 0.45 & 0.50 & 0.55 & 0.60 & 0.64 & 0.68 & 0.72 & 0.75 & 0.78 & 0.81 & 0.84 & 0.86 & 0.88 & 0.89 & 0.91 & 0.92 & 0.93 \\ 0.06 & 0.09 & 0.13 & 0.14 & 0.22 & 0.27 & 0.32 & 0.38 & 0.43 & 0.48 & 0.54 & 0.58 & 0.63 & 0.67 & 0.71 & 0.74 & 0.77 & 0.80 & 0.83 & 0.85 & 0.87 & 0.89 & 0.90 & 0.91 & 0.93 & 0.94\end{array}$ $\begin{array}{lllllllllllllllllllllllllllll}0.05 & 0.07 & 0.10 & 0.14 & 0.18 & 0.23 & 0.29 & 0.34 & 0.39 & 0.45 & 0.50 & 0.55 & 0.60 & 0.64 & 0.68 & 0.72 & 0.75 & 0.78 & 0.81 & 0.84 & 0.86 & 0.88 & 0.89 & 0.91 & 0.92 & 0.93 \\ 0.06 & 0.09 & 0.13 & 0.17 & 0.22 & 0.27 & 0.32 & 0.38 & 0.43 & 0.48 & 0.54 & 0.58 & 0.63 & 0.67 & 0.71 & 0.74 & 0.77 & 0.80 & 0.83 & 0.85 & 0.87 & 0.89 & 0.90 & 0.91 & 0.93 & 0.94\end{array}$

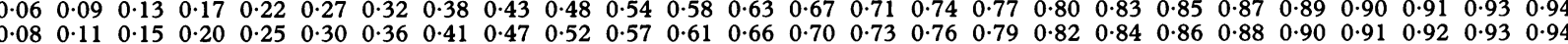
$\begin{array}{llllllllllllllllllllllllllllll}0.10 & 0.14 & 0.18 & 0.23 & 0.28 & 0.34 & 0.39 & 0.45 & 0.50 & 0.55 & 0.60 & 0.64 & 0.68 & 0.72 & 0.75 & 0.78 & 0.81 & 0.83 & 0.86 & 0.87 & 0.89 & 0.91 & 0.92 & 0.93 & 0.94 & 0.95\end{array}$ $\begin{array}{lllllllllllllllllllllllllll}0.13 & 0.17 & 0.21 & 0.27 & 0.32 & 0.37 & 0.43 & 0.48 & 0.53 & 0.58 & 0.63 & 0.67 & 0.71 & 0.74 & 0.77 & 0.80 & 0.83 & 0.85 & 0.87 & 0.89 & 0.90 & 0.91 & 0.93 & 0.94 & 0.94 & 0.95\end{array}$ $\begin{array}{lllllllllllllllllllllllllll}0.15 & 0.20 & 0.25 & 0.30 & 0.35 & 0.41 & 0.46 & 0.52 & 0.57 & 0.61 & 0.65 & 0.69 & 0.73 & 0.76 & 0.79 & 0.82 & 0.84 & 0.86 & 0.88 & 0.90 & 0.91 & 0.92 & 0.93 & 0.94 & 0.95 & 0.96\end{array}$ $\begin{array}{llllllllllllllllllllllllll}0.18 & 0.23 & 0.28 & 0.34 & 0.39 & 0.44 & 0.50 & 0.55 & 0.60 & 0.64 & 0.68 & 0.72 & 0.75 & 0.78 & 0.81 & 0.83 & 0.85 & 0.87 & 0.89 & 0.90 & 0.92 & 0.93 & 0.94 & 0.95 & 0.95 & 0.96\end{array}$ $\begin{array}{lllllllllllllllllllllllllllll}0.21 & 0.26 & 0.32 & 0.37 & 0.43 & 0.48 & 0.53 & 0.58 & 0.63 & 0.67 & 0.71 & 0.74 & 0.77 & 0.80 & 0.83 & 0.85 & 0.87 & 0.88 & 0.90 & 0.91 & 0.92 & 0.93 & 0.94 & 0.95 & 0.96 & 0.96\end{array}$ $\begin{array}{llllllllllllllllllllllllllll}0.25 & 0.30 & 0.35 & 0.41 & 0.46 & 0.51 & 0.56 & 0.61 & 0.65 & 0.69 & 0.73 & 0.76 & 0.79 & 0.82 & 0.84 & 0.86 & 0.88 & 0.89 & 0.91 & 0.92 & 0.93 & 0.94 & 0.95 & 0.96 & 0.96 & 0.97\end{array}$ $\begin{array}{lllllllllllllllllllllllllll}0.28 & 0.33 & 0.39 & 0.44 & 0.50 & 0.55 & 0.59 & 0.64 & 0.68 & 0.72 & 0.75 & 0.78 & 0.81 & 0.83 & 0.85 & 0.87 & 0.89 & 0.90 & 0.92 & 0.93 & 0.94 & 0.95 & 0.95 & 0.96 & 0.97 & 0.97\end{array}$ $\begin{array}{lllllllllllllllllllllllllllll}0.31 & 0.37 & 0.42 & 0.48 & 0.53 & 0.58 & 0.62 & 0.67 & 0.70 & 0.74 & 0.77 & 0.80 & 0.82 & 0.85 & 0.87 & 0.88 & 0.90 & 0.91 & 0.92 & 0.93 & 0.94 & 0.95 & 0.96 & 0.96 & 0.97 & 0.97\end{array}$ $\begin{array}{llllllllllllllllllllllllll}0.35 & 0.40 & 0.46 & 0.51 & 0.56 & 0.61 & 0.65 & 0.69 & 0.73 & 0.76 & 0.79 & 0.82 & 0.84 & 0.86 & 0.88 & 0.89 & 0.91 & 0.92 & 0.93 & 0.94 & 0.95 & 0.96 & 0.96 & 0.97 & 0.97 & 0.98 \\ 0.39 & 0.44 & 0.49 & 0.54 & 0.59 & 0.64 & 0.68 & 0.72 & 0.75 & 0.78 & 0.81 & 0.83 & 0.85 & 0.87 & 0.89 & 0.90 & 0.92 & 0.93 & 0.94 & 0.95 & 0.95 & 0.96 & 0.96 & 0.97 & 0.97 & 0.98\end{array}$ $\begin{array}{llllllllllllllllllllllllll}0.39 & 0.44 & 0.49 & 0.54 & 0.59 & 0.64 & 0.68 & 0.72 & 0.75 & 0.78 & 0.81 & 0.83 & 0.85 & 0.87 & 0.89 & 0.90 & 0.92 & 0.93 & 0.94 & 0.95 & 0.95 & 0.96 & 0.96 & 0.97 & 0.97 & 0.98 \\ 0.42 & 0.48 & 0.53 & 0.58 & 0.62 & 0.66 & 0.70 & 0.74 & 0.77 & 0.80 & 0.82 & 0.85 & 0.87 & 0.88 & 0.90 & 0.91 & 0.92 & 0.93 & 0.94 & 0.95 & 0.96 & 0.96 & 0.97 & 0.97 & 0.98 & 0.98\end{array}$

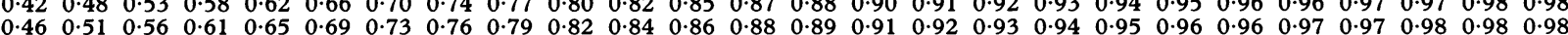

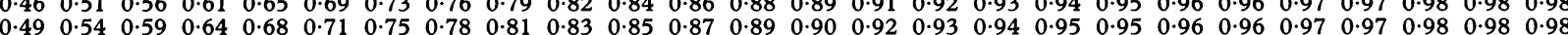

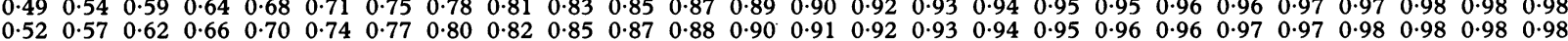

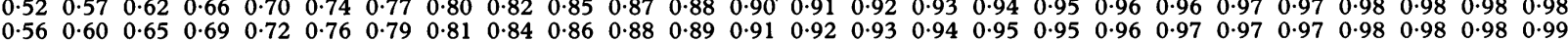

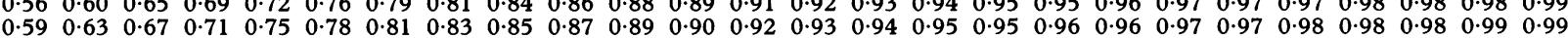

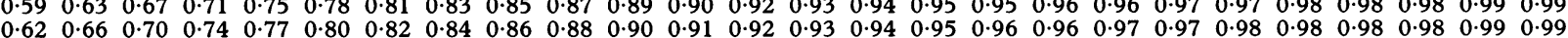

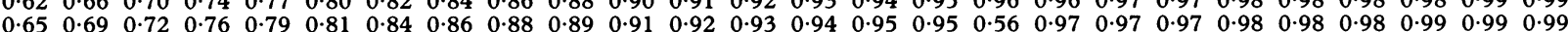

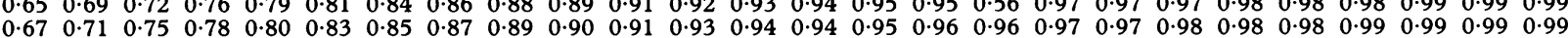
$\begin{array}{llllllllllllllllllllllllll}0.67 & 0.71 & 0.75 & 0.78 & 0.80 & 0.83 & 0.85 & 0.87 & 0.89 & 0.90 & 0.91 & 0.93 & 0.94 & 0.94 & 0.95 & 0.96 & 0.96 & 0.97 & 0.97 & 0.98 & 0.98 & 0.98 & 0.99 & 0.99 & 0.99 & 0.99 \\ 0.70 & 0.73 & 0.77 & 0.79 & 0.82 & 0.84 & 0.86 & 0.88 & 0.90 & 0.91 & 0.92 & 0.93 & 0.94 & 0.95 & 0.96 & 0.96 & 0.97 & 0.97 & 0.98 & 0.98 & 0.98 & 0.98 & 0.99 & 0.99 & 0.99 & 0.99\end{array}$

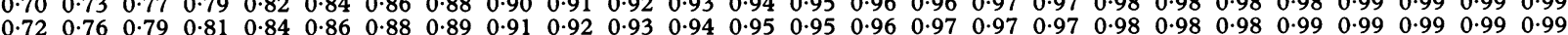

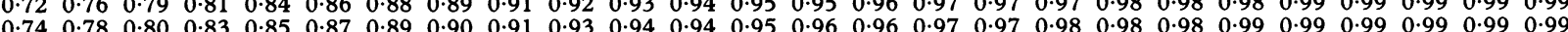

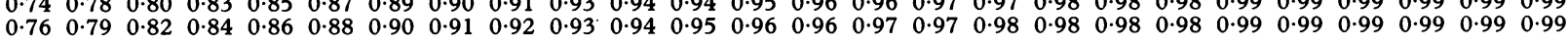


Cumulative survival without death or deterioration to status 1

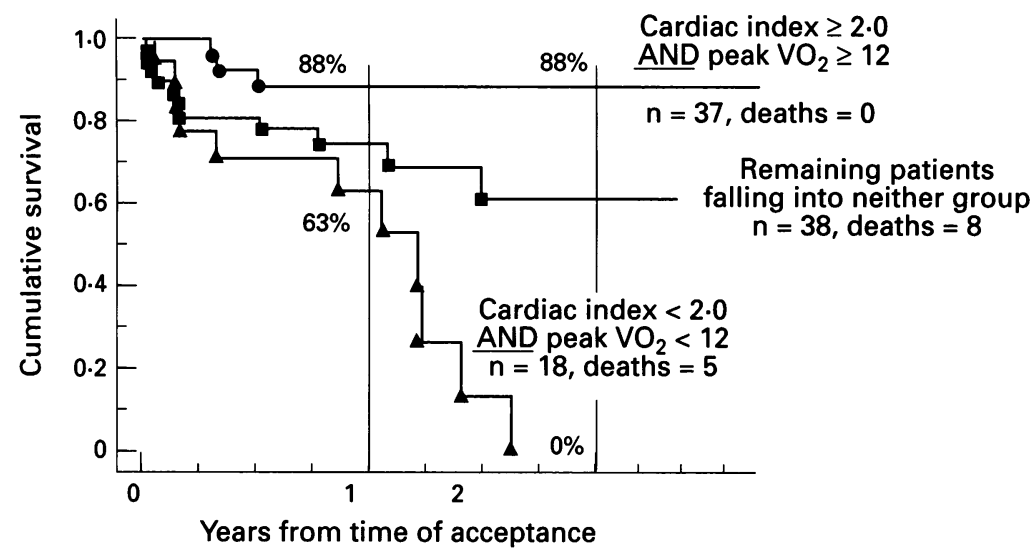

Figure 4 Cumulative survival (Kaplan-Meier curves) without death or deterioration to status 1 in patients who were classified as status 2 at the time of acceptance. Patient groups are stratified in relationship to combinations of measurements of cardiac index and peak oxygen consumption (peak $\mathrm{VO}_{2}$ ). Percentage survival at one and two years is shown.

for a unit increase from a baseline peak oxygen consumption of $12 \mathrm{ml} / \mathrm{min} / \mathrm{m}^{2}$ was $-0 \cdot 195$. The baseline survival function for a cardiac index of 2.0 and a peak $\mathrm{Vo}_{2}$ of 12 was 0.8795 at $60 \mathrm{~d}$ and 0.7508 at one year. From these values survival functions were calculated for a wide range of different combinations of cardiac index and peak $\mathrm{VO}_{2}$ at these two time points (table 4). For example a patient with a peak $\mathrm{VO}_{2}$ of $13.0 \mathrm{ml} / \mathrm{kg} / \mathrm{min}$ and a cardiac index of $2.4 \mathrm{litres} / \mathrm{min} / \mathrm{m}^{2}$ would have a predicted chance of surviving without death or deterioration to status 1 of $94 \%$ at $60 \mathrm{~d}$ and of $88 \%$ at one year. In contrast, a patient with a peak $\mathrm{Vo}_{2}$ of $11.0 \mathrm{ml} / \mathrm{kg} / \mathrm{min}$ and a cardiac index of 1.8 litres $/ \mathrm{min} / \mathrm{m}^{2}$ would have a predicted chance of surviving without death or deterioration to status 1 of only $81 \%$ at $60 \mathrm{~d}$ and of $63 \%$ at one year.

\section{Discussion}

Estimates from the 24th Bethesda conference on heart transplantation ${ }^{1}$ were that in the USA alone 40000 people under 65 who might benefit from a heart transplant die each year, but the number of donor hearts available per year is currently around 2000 . The number of patients awaiting heart transplants in 1993 was approximately 2500, with 300 new patients being added and 150 patients being transplanted per month. Stevenson et $a l^{2}$ have projected that within less than four years the candidate pool will reach 4000 patients, $93 \%$ of whom will be outpatients, but only the 270 critically ill candidates in hospital at any one time will have a chance of receiving a donor organ.

ANALYSIS OF DEATHS ON THE WATTING LIST

The growing imbalance between the number of donor organs available and the number of candidates has resulted in increases in waiting time, and the number of deaths on the waiting list reported to the United Network for Organ Sharing (UNOS) has been rising steadily, from
98 in the last quarter of 1987 to 207 in the last quarter of $1991 .^{3}$ The parallel increase in waiting time and rate of death on the waiting list is also seen in the data from our centre reported in this study. The mean waiting time for all patients between 1 January 1991 and 31 May 1994 was 272 days, with a death rate over this period of $16 \%$. Mean waiting time has not been reported by UNOS since 1989 but figures for the overall percentage ratio between patients accepted onto the waiting list in 1991 and deaths on the waiting list in the same year (the comparable figure to the rate we report) can be estimated from reported UNOS data to be $22 \%$.

\section{CLINICAL VARIABLES AS PROGNOSTIC INDICATORS}

Reporting on the current situation regarding the use of clinical variables to risk stratify the heart transplant waiting list, Task Force 3 at the 1993 Bethesda conference observed that " $a$ few studies have used multivariate techniques to predict survival, but no consistent objective clinical criteria have emerged". ${ }^{1}$ The variable which has drawn most attention is the peak $\mathrm{VO}_{2}{ }^{1}{ }^{5-10}$ Although values of $10,{ }^{9} 11,{ }^{8} 12,{ }^{7} 14,{ }^{6}$ and $20^{10}$ have all been proposed as useful dichotomisation points to identify high or low risk subsets, the value most widely accepted derives from the observation by ourselves ${ }^{5}$ and by Mancini et $a l^{6}$ that patients with peak $\mathrm{Vo}_{2}$ greater than 14 $\mathrm{ml} / \mathrm{kg} / \mathrm{min}$ were a relatively good prognosis group in whom heart transplantation could be deferred. In the Task Force 3 report, a $\mathrm{Vo}_{2}$ less than $14 \mathrm{ml} / \mathrm{kg} / \mathrm{min}$ is given as a probable indication for heart transplantation, although the report did not go so far as to include this figure in its recommendations. The use of the policy suggested by Mancini et al of deferring transplantation in patients with $\mathrm{Vo}_{2}$ greater than 14 $\mathrm{ml} / \mathrm{kg} / \mathrm{min}$ would have excluded $33 \%$ of the status 2 patients from the waiting list (slightly less than the $39 \%$ excluded by the application of cardiac index $\geqslant 2.0$ litres $/ \mathrm{min} / \mathrm{m}^{2}$ and peak $\mathrm{Vo}_{2}$ $\geqslant 12 \mathrm{ml} / \mathrm{kg} / \mathrm{min}$ in our study); however $15 \%$ of all deaths in the status 2 patients occurred in patients with $\mathrm{Vo}_{2}$ greater than 14. Furthermore these deaths all occurred within two months from the time of acceptance; the three monthly reassessment of peak $\mathrm{VO}_{2}$ advised in conjunction with this policy would therefore not have helped these patients. Using the strategy of cardiac index $\geqslant 2.0$ litres $/ \mathrm{min} / \mathrm{m}^{2}$ and peak $\mathrm{Vo}_{2}$ $\geqslant 12 \mathrm{ml} / \mathrm{kg} / \mathrm{min}$, there were no deaths during follow up in patients satisfying both criteria.

While cardiac output has been identified as an independent prognostic indicator in at least one other study, ${ }^{11}$ several other variables such as low serum sodium, raised pulmonary artery diastolic pressure, left ventricular end diastolic dilatation, permanent pacing, ${ }^{8}$ aetiology, New York Heart Association class, third heart sound, pulmonary wedge pressure, and mean systemic blood pressure ${ }^{11}$ have also been found to be independent risk factors for death in patients either accepted or referred for heart transplantation. Some of these variables were significant univariate predictors of death in our series, but only peak $\mathrm{VO}_{2}$ and cardiac index were indepen- 
dently significant on multivariate analysis. Another study of prognosis in patients evaluated, but not necessarily accepted, for heart transplantation did not find cardiac index to be a useful prognostic indicator. ${ }^{12}$ However, the measurements of cardiac index analysed in that series were made after a period of intensive medical treatment guided by pulmonary flotation catheter monitoring. Thus the mean values for pulmonary capillary wedge pressure in that group were approximately $15 \mathrm{~mm} \mathrm{Hg}$, considerably lower than the mean values of 23-24 $\mathrm{mm} \mathrm{Hg}$ seen in our patients at the time of initial evaluation. Interestingly the same investigators observed that in their series, cardiac index values above or below 2.5 litres/ $\mathrm{min} / \mathrm{m}^{2}$ had a significant effect on survival $(P=$ $0.0005)$ in patients who were receiving hydralazine and nitrates rather than angiotensin converting enzyme inhibitors and nitrates. While the ability to respond to treatment by achieving pulmonary capillary wedge pressures below $15 \mathrm{~mm} \mathrm{Hg}$ may be a further useful prognostic indicator, this type of intensive inpatient "tailoring" of treatment is expensive and a prognostic strategy that can be applied without the need to perform therapeutic manipulation guided by central haemodynamic monitoring may be of practical value in many centres.

One of the main problems in applying fixed indices as practical tools for making decisions over which patients should go on to the heart transplant waiting list has been the tendency for most studies to report the results as survival curves for groups of patients termed low or high risk. The problem facing a transplant cardiologist is to apply mean survival values for a group, which includes a wide range of different values, to a patient who may have a measured value just above or below the cut off value. Although extrapolation from the results of this study must be undertaken with caution as the patient population may not be representative of all centres and the data have not been tested prospectively, the tables giving the predicted chance of survival without death or deterioration to status 1 for patients with specific values of cardiac index and peak $\mathrm{Vo}_{2}$ may be useful in determining which patients may have a worse chance of surviving one year if transplanted than if maintained on medical treatment. It should be emphasised that the single centre nature of the study and the limited sample size may result in the power of risk stratification achieved by the use of cardiac index and peak $\mathrm{Vo}_{2}$ varying when applied to different populations.

It has been suggested that patients who have survived on the waiting list for over nine months do not to derive survival benefit from transplantation, ${ }^{13}$ and it has been proposed that patients who have survived on the list for this time should be removed from the waiting list. ${ }^{2}$ It is clearly preferable, however, to exclude patients who will not gain survival benefit from transplantation at the time of evaluation, rather than after nine months on the list. While reduction of the current candidate pool may be facilitated by such a removal policy, it may be difficult for patients to feel confidence in a decision removing them after they have been on the waiting list for nine months. There is also a risk in centres with small waiting lists and few patients with less common blood groups that chance fluctuations in the availability of hearts of a particular blood group may result in patients with a good medium term outlook being transplanted inappropriately within the nine month period. Survival probability tables of the type presented here provide an alternative approach to the management of such patients who are borderline for placement on the heart transplant waiting list.

The anticipated reduction in status 2 patients of $39 \%$ using the cardiac index $\geqslant 2.01 / \mathrm{min} / \mathrm{m}^{2}$ and peak $\mathrm{Vo}_{2} \geqslant 12 \mathrm{ml} / \mathrm{kg} / \mathrm{min}$ criteria (or a similar reduction using a one year death and deterioration survival function of 0.75 ) also compares favourably with the age restriction to an upper limit of 55 years which it has been suggested would achieve a $30 \%$ reduction in the waiting list ${ }^{2}$ and would avoid excluding patients on the grounds of age who have been found to have results from transplantation comparable to those of younger patients. ${ }^{14}$

\section{BENEFITS IN PERIOPERATIVE MORBIDITY AND MORTALITY}

In our study $14 \%$ of patients who were status 2 at the time of acceptance were transplanted after progression to status 1 . If this number could be reduced, there is evidence that this would decrease perioperative morbidity and mortality. Reports of the influence of requirement for inotropic or mechanical support before cardiac transplantation on mortality following surgery show some variation between centres but overall show worse survival after transplantation in patients transplanted from status 1 than with those transplanted from status 2 . One year survival in status 1 patients who have undergone transplantation has been found to be between $69 \%{ }^{15}$ and $83 \%,{ }^{16}$ with certain subgroups showing a particularly high postoperative mortality. It appears that the combination of the requirement for status 1 support and the presence of pulmonary hypertension is very unfavourable, with a three month actuarial survival of only $30 \cdot 3 \% .{ }^{17}$ Although UNOS data do not allow a direct comparison of status 1 and status 2 patients survival following transplantation, Bethesda task force 1 reported a one year survival of $74 \%$ for patients requiring ventilation, intra-aortic counterpulsation, or left ventricular assistance before transplantation, with all other groups having a one year survival greater than $80 \% .^{18}$

\section{MANAGEMENT STRATEGIES FOR HIGH RISK \\ STATUS 2 PATIENTS}

Reducing the size of the status 2 waiting list by avoiding accepting patients who are unlikely to gain survival benefit from transplantation will tend to reduce the time to transplantation for the higher risk status 2 patients who remain on the waiting list. However, it is unlikely that this measure alone will be sufficient to reduce the waiting time to within two months from the time of acceptance. In our patient population, the majority of status 2 patients who died on the waiting list did so within two months from the 
time of acceptance for transplantation. To reduce the numbers of status 2 patients dying on the waiting list it would therefore be necessary to identify a high risk subset in which early intervention was warranted. Such a high risk subgroup could be transplanted ahead of lower risk patients on the waiting list rather than waiting in chronological order of acceptance, but this would disadvantage the remaining patients on the waiting list. An alternative approach might be to consider entering particularly high risk patients into prospective trials for new treatments, such as elective implantable left ventricular assistance devices or implantable defibrillator insertion. The value of such devices when applied to this particular population is currently unknown, but data on survival when implantable left ventricular assistance devices are used in status 1 patients are very favourable, particularly after a delay to allow organ recovery, ${ }^{19}$ and although such devices have had a less impressive impact when applied to patients with poor left ventricular function and recurrent arrhythmias $^{20}$ a prospective trial is warranted. By retrospective interrogation of the devices, this would provide valuable information on the type of arrhythmias experienced in these patients.

\section{SUMMARY}

In this study, status 2 patients who were accepted onto the heart transplant waiting list with cardiac index $\geqslant 2.0$ litres $/ \mathrm{min} / \mathrm{m}^{2}$ and peak $\mathrm{VO}_{2} \geqslant 12 \mathrm{ml} / \mathrm{kg} / \mathrm{min}$ had a one year mortality of zero and a rate of deterioration to status 1 of $12 \%$. Such patients may therefore have a worse prognosis following transplantation than if they continue with medical treatment alone. Conversely, status 2 patients with cardiac index $\leqslant 2 \cdot 0$ litres $/ \mathrm{min} / \mathrm{m}^{2}$ and peak $\mathrm{Vo}_{2} \leqslant 12$ $\mathrm{ml} / \mathrm{kg} / \mathrm{min}$ had a very poor prognosis on the waiting list. Using tables of the type constructed here from a Cox proportional hazards model, it may be possible to predict risk of death or deterioration to status 1 from measurements of cardiac index and peak $\mathrm{VO}_{2}$ in individual patients. This approach could be used to specify patients for whom it would be appropriate either to avoid transplantation and continue with medical treatment, or to consider early transplantation or entry into trials of new treatments. These criteria should be tested retrospectively on waiting list data bases in other populations and could form the basis for a prospective multicentre randomised trial designed to assess the value of the strategy described in the management of status 2 patients being listed for heart transplantation.

We would like to thank Dr Bill Brown and for assistance with statistical design, Cheryl Barry for expert assistance with data processing, and Kathy Wilson RN and Lisa Prikazsky RN for invaluable assistance with out-patient monitoring and data collection. PTT was supported by a training grant from the lection. PTT was supported by a training gra
Geneva University Hospital, Geneva, Switzerland.

1 Mudge G, Goldstein S, Addonizio L, et al. 24th Bethesda Conference. Task Force 3. Recipient guidelines/prioritization. $\mathcal{A}$ Am Coll Cardiol 1993;22:21-31.

2 Stevenson L, Warner S, Steimle A, et al. The impending crisis awaiting cardiac transplantation: a modeling solution based on selection. Circulation 1994;89:450-7.

McManus R, O'Hair D, Beitzinger J, et al. Patients who die awaiting heart trans

4 Stevenson L, Warner S, Hamilton M, et al. Distribution of Stevenson $\mathrm{L}$, Warner S, Hamilton $\mathrm{M}$, et al. Distribution of
donor heart to maximise transplant candidate survival donor heart to maximise transplant candid

5 Singer A, Vagellos R, Wilson K, Nejedly M, Fowler M. Measurement of maximal oxygen consumption is of value in the selection of patients for cardiac transplantation [abstr]. F Am Coll Cardiol 1991;17(suppl A):57A

6 Mancini D, Eisen H, Kussmaul W, Mull R, Edmunds L, Wilson J. Value of peak exercise oxygen consumption for optimal timing of cardiac transplantation in ambulatory patients with heart failure. Circulation 1991;83: 778-86

7 Stevenson L, Stiemle A, Chelimsky-Fallick C, et al. Ability to improve exercise capacity identifies heart transplan candidates who should leave the waiting list [abstr]. Circulation 1992;86(suppl I):I-809.

8 Saxon L, Stevenson W, Middlekauff H, et al. Predicting death from progressive heart failure secondary to ischemic or idiopathic dilated cardiomyopathy. $A m \mathcal{f}$ Cardiol 1993;72:62-5.

9 Stevenson L, Steimle A, Chelimsky-Fallick C, et al. Outcomes predicted by peak oxygen consumption during evaluation of 333 patients with advanced heart failure evaluation of 333 patients with advanced
[abstr]. Circulation 1993;88(suppl I):I-94.

10 Kubo S, Ormaza S, Francis G, et al. Trends in patient selection for heart transplantation. $f$ Am Coll Cardiol 1993;21:975-81.

11 Campana C, Gavazzi A, Beruizini C, et al. Predictors of prognosis in patients awaiting heart transplantation. $f$ Heart Lung Transplant 1993;12:756-65.

12 Stevenson L, Fonarow G, Hamilton M, Tillisch J. Why cardiac output is not a good hemodynamic target for therapy in advanced heart failure [abstr]. Circulation 1994;90:I-611.

13 Stevenson L, Hamilton $M$, Tillisch I, et al. Decreasing survival benefit from cardiac transplantation for outpatients as the waiting list lengthens. F Am Coll Cardiol 1991; 18:919-25.

14 Olivari M, Antolick A, Kaye M, Jamieson S, Ring W. Heart transplantation in elderly patients. $\mathcal{F}$ Heart Transplant 1988;7:258-64.

15 Mulcahy D, Wright C, Mockus L, Yacoub M, Fox K. Cardiac transplantation in severely ill patients requiring intensive support in hospital. BMF 1988;296:817-9.

16 O'Connell J, Renlund D, Robinson J, et al. Effect of preoperative hemodynamic support on survival after cardiac transplantation. Circulation 1988; 78(suppl III):III-78-82.

17 Costard-Jäckle A, Hill I, Schroeder J, Fowler M. The influence of preoperative patient characteristics on early and
late survival following transplantation. Circulation 1991; 84(suppl III):III-329-37.

18 O'Connell J, Gunnar R, Evans R, Fricker F, Hunt S, Kirklin J. 24th Bethesda Conference. Task Force 1: Organisation of Heart Transplantation in the US. $f \mathrm{Am}$ Col Cardiol 1993;22:8-14.

19 Frazier O, Macris M, Myers T, et al. Improved survival Frazier O, Macris M, Myers T, et al. Improved survival
after extended bridge to cardiac transplantation. Ann
Thorac Surg 1994;57:1416-22.

$20 \mathrm{Kim}$ S, Maloney J, Pinski S, et al. Influence of left ventricular function on survival and mode of death after implantable defibrillator therapy (Cleveland Clinic Foundation and Montefiore Medical Center experience). Am f Cardiol 1993;72:1263-7. 